\title{
Post-Delivery Hypoglycemia in Type 1 Diabetic Patient is associated with Lactation: A Case Presentation
}

\author{
José G Jiménez-Montero*
}

Department of Endocrinology Hospital CIMA, San José, Costa Rica and Postgraduate Studies, Universidad de Ciencias Médicas, PO Box 638 -1007, Centro Colon, San José, Costa Rica

\section{Article Info}

*Corresponding author:
José G Jiménez-Montero
Department of Endocrinology Hospital CIMA
San José, Costa Rica and Postgraduate
Studies
Universidad de Ciencias Médicas
PO Box 638 -1007, Centro Colon
San José, Costa Rica
Tel: 50625490128
E-mail: jimenezmj@ucimed.com;
jjimenez@hospitalcima.com

Received: September 28, 2015

Accepted: October 20, 2015

Published: October 28, 2015

Citation: Jiménez-Montero JG. Post-Delivery Hypoglycemia in Type 1 Diabetic Patient is associated with Lactation: A Case Presentation. Madridge J Diabetes. 2015; 1(1): 5-10.

doi: 10.18689/mjd-1000102

\section{Copyright: @ 2015 The Author(s). This work is licensed under a Creative Commons Attribution 4.0 International License, which permits unrestricted use, distribution, and reproduction in any medium, provided the original work is properly cited.}

Published by Madridge Publishers

\begin{abstract}
Objective: To describe diabetes management during pregnancy and after delivery of a pregnant type-I diabetic patient with hyperemesis gravidarum.
\end{abstract}

Methods: The patient's history, laboratory results, and glycemic control were obtained. Diabetes control was done using an insulin pump and a glucose monitoring system during pregnancy, post-partum and at six month after delivery.

Results: A 27-year-old pregnant patient with history of hypothyroidism, type 1 diabetes, and hyperemesis gravidarum, receiving multiple daily insulin injections, presented marked glycemic fluctuations starting on week 6 of gestation. Before conception laboratory results showed glycosylated hemoglobin $\mathrm{A} 1 \mathrm{c}(\mathrm{HbA} 1 \mathrm{c})$ at $6.7 \%$ and ThyroidStimulating Hormone (TSH) at $4.40 \mathrm{uUl} / \mathrm{ml}$. An insulin pump and a continuous glucose monitoring system improved glycemic control as mean glucose changed from $139 \pm 77$ $\mathrm{mg} / \mathrm{dL}$ in the first trimester to $113.0 \pm 44 \mathrm{mg} / \mathrm{dL}$ and $106.0 \pm 39 \mathrm{mg} / \mathrm{dL}$, in the second and third trimester $(\mathrm{p}<0.01)$ respectively. $\mathrm{HbA}_{1 \mathrm{c}}$ declined from $6.7 \%$ to $5.6 \%$. Adjustment in levothyroxine doses optimized thyroid hormone levels. The patient gave birth on week 39 of pregnancy by Caesarean section to a child of 2,700 g and $48 \mathrm{~cm}$, and an Apgar score of 9/10. Recurrently poglycemic episodes occurred 10-15 minutes after initiating lactation followed by rebound hyperglycemic events; once the patient ceased lactation six months later glycemic controls improved.

Conclusions: Optimal glycemic control was achieved during pregnancy, but the lactation period induced sudden glucose fluctuations. Recurring hypoglycemic events lead to a decline in post-partum glycemic control. Thus, lactation-induced hypoglycemia may explain the frequent deterioration in glycemic control in type-I diabetic patients.

Keywords: Type 1 diabetes; Lactation-induced hypoglycemia; Continuous insulin infusion; Continuous glucose monitoring system.

Abbreviation: TSH: Thyroid-Stimulating Hormone; CSII: Continuous Insulin Infusion; CGMS: Glucose Monitoring System

\section{Introduction}

In diabetic pregnant patients, a strict glycemic control is critical to avoid fetal malformations, neonatal morbidity and obstetrical complications [1-5]. However, in type 1 diabetics an aggressive insulin treatment increases the risk of severe hypoglycemia and has potential adverse maternal effects $[6,7]$. Recurrent hypoglycemic events induce rebound hyperglycemia due to counter regulatory mechanisms and food intake [8]. Postprandial hyperglycemia during pregnancy has been identified as the best prognosis of neonatal macrosomia, despite excellent $\mathrm{HbA}_{1} \mathrm{c}$ levels throughout pregnancy [9]. Moreover, glycemic fluctuations may adversely affects diabetic complications [10]. 
This case study first describes the clinical course of a type 1 diabetic pregnant patient suffering from hyperemesis gravidarum since the first trimester up until six months postpartum. Secondly, it documents the occurrence of sudden glycemic reductions and recurrent hypoglycemic events soon after beginning the lactation period.

\section{Case Presentation}

A 27-year-old, Venezuelan, type 1 diabetic patient, receiving treatment with multiple daily insulin injections (16 U glargine insulin plus $10 \mathrm{U}$ prandial lispro insulin) came to the clinic for a regular check-up. She followed an adequate diet, was engaged in regular physical activity, and performed selfmonitoring blood glucose tests three times a day. During the first visit to the clinic her $\mathrm{HbA}_{1 \mathrm{c}}$ was at $6.2 \%$, there was no evidence of diabetic-related complications. She had rare symptomatic or unawareness hypoglycemic episodes. At age 24 she was diagnosed with hyperthyroidism. She was treated with radioactive iodine, developing hypothyroidism. She was treated with 125 uglevothyroxine daily, and was tested for TSH receptor antibodies resulting in negative findings. Her thyroid-stimulating hormone (TSH) level was $3.96 \mathrm{uUI} / \mathrm{ml}$. The patient's blood pressure was $90 / 60 \mathrm{mmHg}$, her height was $159 \mathrm{~cm}$, weight $50.7 \mathrm{~kg}$ and Body Mass Index (BMI) $20.6 \mathrm{~kg} /$ $\mathrm{mts}$ [2]. There were no outstanding findings in the physical examination. Minor adjustments in insulin and levothyroxine doses were done.

The second visit occurred three months later when the patient reported nausea, daily vomiting, and nocturnal and post-exercise hypoglycemia. The patient's finger stick test glucose levels fluctuated from $40-290 \mathrm{mg} / \mathrm{dL}$ at any time of the day. She was found to be six weeks pregnant with hyperemesis gravidarum. Her $\mathrm{HbA}_{1} \mathrm{c}$ was at $6.7 \%$ and the TSH was at $4.4 \mathrm{uUI} / \mathrm{ml}$. Her weight was $52 \mathrm{~kg}$ and blood pressure $90 / 70 \mathrm{mmHg}$. Glargine insulin was discontinued, prandial insulin was reduced to $6 \mathrm{U}$, and levemir $16 \mathrm{U}$ was initiated. Domperidone $10 \mathrm{mg}$ and folic acid $5 \mathrm{mg}$ were prescribed.

One week later, the patient continued vomiting and experiencing severe and recurrent hypoglycemic events and rebound postprandial hyperglycemia. She was hospitalized, and a Continuous Insulin Infusion (CSII) (Paradigm Medtronic, Minneapolis, MN) and Glucose Monitoring System (CGMS, Medtronic, Northridge, CA) were placed $[10,11]$ in order to improve glucose control [11-15]. During a short inpatient period, we conducted carbohydrate counting and insulin pump management sessions. The insulin infusion rate was determined based on the total MDI regimen previously used and adjusted according to daily glucose profiles.

The patient's weight rose to $57.5 \mathrm{~kg}$ and $61 \mathrm{~kg}$ during the second and third trimester, respectively. She maintained normal blood pressures, did not have albuminuria, and sequential ultrasounds did not reveal fetal abnormalities. On week 39 the patient gave birth to a child of $2,700 \mathrm{~g}, 48 \mathrm{~cm}$, and an Apgar score of $9 / 10$, by cesarean section with no complications and no evidence of thyrotoxicosis. The patient received a $5 \%$ glucose IV infusion while the CSII was still in place. Immediately after delivery, the insulin infusion was stopped transitorily, and then re-started at a reduced infusion rate. Glucose levels ranged between $120-140 \mathrm{mg} / \mathrm{dl}$ during the following hours. The patient was counseled to adjust her food intake, and began breastfeeding eight hours after delivery. In the next three months, she noticed abrupt glycemic declines 10-15 minutes after she began breast feeding, followed by rebound hyperglycemia.

The patient was under observation to monitor the fluctuation glucose levels. She did not perform physical activity during this time. The patient ceased lactation and had gradual improvements in glucose control with few hypoglycemic levels compared to the previous months. After the patient stopped breastfeeding, she occasionally extracted breast milk manually to feed her baby and to avoid mastitis. Interestingly, doing so caused glycemic declines minutes after milk extraction. This observation was not documented with the CGMS.

The changes in $\mathrm{HbA}_{1}$, blood glucose, the area under the curve above and below target levels, the standard deviation of glucose, and the glucose variation coefficient were analyzed during pregnancy, in the early post-partum period and three and six months later. Compared to the first trimester, the glucose variation coefficient declined from $55 \%$ to $13.5 \%$ and the area under the curve above target was reduced by $77 \%$ at the end of pregnancy, as illustrated in Table 1 and Figure 1. The average daily carbohydrate intake, average daily insulin, and the carbohydrate/insulin ratio during pregnancy and post-partum periods were obtained from the CGMS, as shown in Table 2. Total insulin requirements increased from $0.55 \mathrm{U} /$ $\mathrm{kg}$ in the first trimester to $0.80 \mathrm{U} / \mathrm{kg}$ at the end of pregnancy; the changes in insulin demand were mainly driven from increments in insulin bolus, which changed from 0.23 to 0.45

\begin{tabular}{|c|c|c|c|c|c|c|c|c|c|}
\hline & \multicolumn{2}{|c|}{ First Trimester } & \multicolumn{2}{|c|}{ Sesond Trimester } & \multicolumn{2}{|c|}{ Third Trimester } & \multicolumn{3}{|c|}{ Post Partum } \\
\hline & Initial & Late & Initial & Late & Initial & Late & 4 Days & 1 month & 6 months \\
\hline $\mathrm{HbA}_{1 \mathrm{c}}(\%)$ & 6.7 & 6.5 & 5.8 & 5.4 & 5.9 & 5.6 & 5.6 & 6.4 & 7.0 \\
\hline Mean Blood Glucose (mg/dl) & $139.0 \pm 77.0$ & $127.0 \pm 49.0^{*}$ & $113.0 \pm 44.0^{*}$ & $124.0 \pm 32.0^{*}$ & $106.0 \pm 39.0^{*}$ & $131.0 \pm 13.5$ & $146.0 \pm 47.0$ & $189.0 \pm 72.0$ & $101.7 \pm 10.4^{*}$ \\
\hline Average AUC above target (mg/dl) & 30.6 & 18.6 & 10.5 & 7.1 & 7.8 & 13.9 & 26.5 & 25.8 & 9.0 \\
\hline Average AUV above targe $(\mathrm{mg} / \mathrm{dl})$ & 0 & 2.4 & 3.5 & 0 & 4.8 & 0.4 & 0.2 & 1.3 & 6.4 \\
\hline SD of Blood Glucose $(\mathrm{mg} / \mathrm{dl})$ & 77.0 & 49.0 & 44.0 & 32.0 & 39.0 & 15.5 & 47.0 & 72.0 & 10.4 \\
\hline$\%$ CV of Blood glucose & 55.4 & 38.6 & 38.9 & 25.8 & 36.8 & 13.5 & 32.2 & 38.0 & 10.3 \\
\hline
\end{tabular}

Results are expressed as mean $+\mathrm{SD}$

${ }^{*} \mathrm{P}=0.001$ as compare to initial first trimerster

Table 1: Diabetes management during pregnancy, after delivery and it six months post partum in a type 1 diabetic patient with hyoeremesis gravidarum 


\begin{tabular}{|c|c|c|c|c|c|c|c|c|c|}
\hline & \multicolumn{2}{|c|}{ First Trimester } & \multicolumn{2}{|c|}{ Sesond Trimester } & \multicolumn{2}{|c|}{ Third Trimester } & \multicolumn{3}{|c|}{ Post Partum } \\
\hline & Initial & Late & Initial & Late & Initial & Late & 3 Days & 1 month & 6 months \\
\hline Average Daily Carbohydates & $163.6 \pm 57.7$ & $164.2 \pm 32.9$ & $203.2 \pm 15.3$ & $237.2 \pm 32.9$ & $212.7 \pm 27.3$ & $197.4 \pm 21.1$ & $213.7 \pm 50.9$ & $200.0 \pm 31.0$ & $156.2 \pm 14.3$ \\
\hline Average Daily Insulin (U) & $29.8 \pm 1.7$ & $36.5 \pm 3.0$ & $39.4 \pm 3.3^{*}$ & $52.8 \pm 3.4^{*}$ & $50.2 \pm 2.2^{*}$ & $48.9 \pm 3.4^{*}$ & $26.0 \pm 4.5$ & $28.6 \pm 2.7$ & $32.2 \pm 1.2$ \\
\hline Total & $17.5 \pm 3.5$ & $17.5 \pm 0.1$ & $17.6 \pm 0.05$ & $20.2 \pm 0.05$ & $20.3 \pm 0.04$ & $21.7 \pm 0.1$ & $11.2 \pm 0.6$ & $14.3 \pm 0.08$ & $20.3 \pm 0.1$ \\
\hline Basal & $12.2 \pm 4.0$ & $18.8 \pm 3.1$ & $22.2 \pm 2.9$ & $32.5 \pm 3.4^{*}$ & $29.9 \pm 2.2^{*}$ & $27.7 \pm 3.4^{*}$ & $14.8 \pm 4.4$ & $14.2 \pm 2.3$ & $11.9 \pm 1.0$ \\
\hline Bolus & $13.3 \pm 1.8$ & $8.7 \pm 0.98$ & $9.3 \pm 0.94$ & $7.27 \pm 0.2$ & $7.0 \pm 0.5$ & $7.3 \pm 0.7$ & $14.7 \pm 1.4$ & $13.2 \pm 1.75$ & $13.1 \pm 1.0$ \\
\hline
\end{tabular}

Results are expressed as mean + SD

*P=0.005 as compare to initial first trimerster

Table 2: Daily carbohydrate intake, insulin doses, and carbohydrates/bolus insulin during pregnancy and post partum

$\mathrm{U} / \mathrm{kg}$ in the same time period. Three days, one month and six months post-partum, insulin requirements dropped, as total daily insulin requirement was $0.44,0.53$ and $0.6 \mathrm{U} / \mathrm{kg}$, respectively. Table 2 shows average daily insulin dose during different trimesters and in the post-partum period.

Due to hyperemesis, the absorption of levothyroxine was affected as TSH increased to $5.0 \mathrm{uU} / \mathrm{ml}$ on week 16 of pregnancy (Figure 2). Thus, levothyroxine was increased to 175 ug daily and, as a result of that, total T4 concentrations ranged from 11.5 to $12.5 \mathrm{ug} / \mathrm{dl}$ and the TSH levels were maintained below $3.0 \mathrm{uUI} / \mathrm{ml}$ during the rest of the pregnancy.

\section{Discussion}

The present report describes a type 1 diabetic hypothyroid female patient with hyperemesis gravidarum who presented large glycemic fluctuations and hypoglycemia during the first weeks of pregnancy. Physical activity was not associated with the glucose fluctuations, as the patient was sedentary during the observation period. This patient did not report unnoted hypoglycemia prior to the pregnancy and, although she was diagnosed with diabetes twenty years ago, no other risk indicators for hypoglycemia were documented [16]. In addition to the glucose variability seen in type 1 pregnant diabetic patients $[8,17]$, hyperemesis gravidarum predisposed severe hypoglycemic episodes. This condition precluded an optimal diabetes management and added high risks to the patient and fetus. The prenatal insulin treatment provided a good glycemic control as $\mathrm{HbA}_{1 \mathrm{c}}$ was at $6.7 \%$, but glucose levels fluctuated along the hyperglycemic and hypoglycemic range, predisposing obstetrical complications and congenital abnormalities, as aforementioned [2,3].

The intensive insulin treatment with CSII has not proven to be superior to $\mathrm{MDI}$ in pregnancy complicated by diabetes $[13,18]$, and macrosomia has been documented in wellcontrolled type 1 diabetics with CSII $[8,9]$. In this patient, the glucose fluctuations were high and she suffered from frequent and severe hypoglycemic events, therefore, the use of both the CSII with the CGMS was clearly indicated $[14,15]$.

As pregnancy progressed, glycemic control improved and glucose recordings significantly declined, similarly to previous studies $[13,18]$. The patient's average carbohydrate intake increased throughout pregnancy and as expected, insulin needs increased. While basal insulin requirements remained relatively constant, the overall insulin demand was provided by the prandial insulin boluses, as reported previously [11-13].

In the post-partum period, the patient experienced unexpected glucose declines and hypoglycemic episodes 1015 min after she initiated lactation as observed previously [19]. In non-diabetic women, no significant glucose changes occur during the period before or after lactation, nor do they develop hypoglycemia in response to lactation [20,21]. Fasting glucose demand was associated with an increased glucose production derived from glycogenolysis; while during breastfeeding, normal glucose levels were maintained by increasing insulin sensitivity [21]. Lactation has beneficial effects on glucose and lipid metabolism [22], and it was shown that the intensity of lactation improved fasting glucose and lower insulin levels as compared to non-lactating women [23]. The basal insulin dose was reduced to minimize the risk of hypoglycemia in breastfeeding in type 1 diabetic patients using CSII $[24,25]$, as done to our patient during the lactation period. Thus, hyperinsulinization does not seem to have played a role in the hypoglycemic episodes seen in our patient. The recurrent falls in the glucose levels and the hypoglycemic episodes documented soon after she initiated breastfeeding could be explained by the increased glucose demand associated with lactation and to the post-partum changes in insulin sensitivity $[21,22]$. In addition to the changes in insulin sensitivity and glucose demand to produce lactose for milk production, other mechanisms, such as the neurohormonal stimulus of suckling, could have elicited this phenomenon. Nevertheless, this is only speculative.

In conclusion, in this type 1 diabetic, hypothyroid, pregnant patient complicated with hyperemesis, who gave birth to a normal child on week 39, the CGMS and CSII had a favorable effect to optimized glucose control. Thus, lactationinduced hypoglycemia could have played a role in the post delivery deterioration of glucose control in our patient.

Acknowledgments: Lic. Kathya Arrieta-Morera for assistance in literature search,to Lic. Grettel Rodrìguez-Rodríguez for technical assistance and to Miss Constanza Gonzalez for their for technical assistance in preparing the manuscript.

Financial Disclosure: Dr. JG. Jiménez-Montero has been on the insulin advisory board, received a research grant from Sanofi-Aventis and has been speaker for Merck Sharp \& Dohme, and Novartis.

Consent: Patient has provided written consent for publication of this study. 


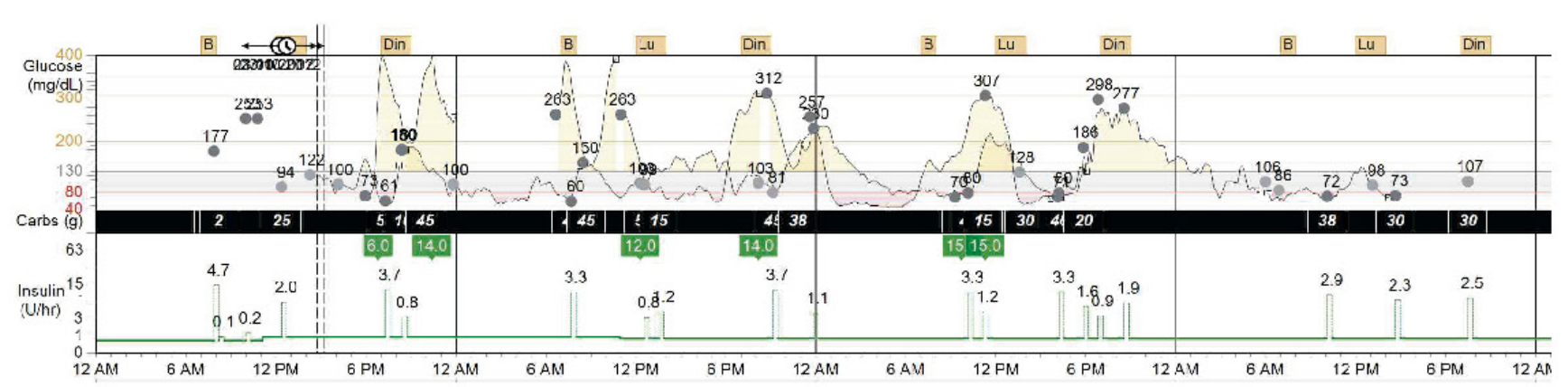

A
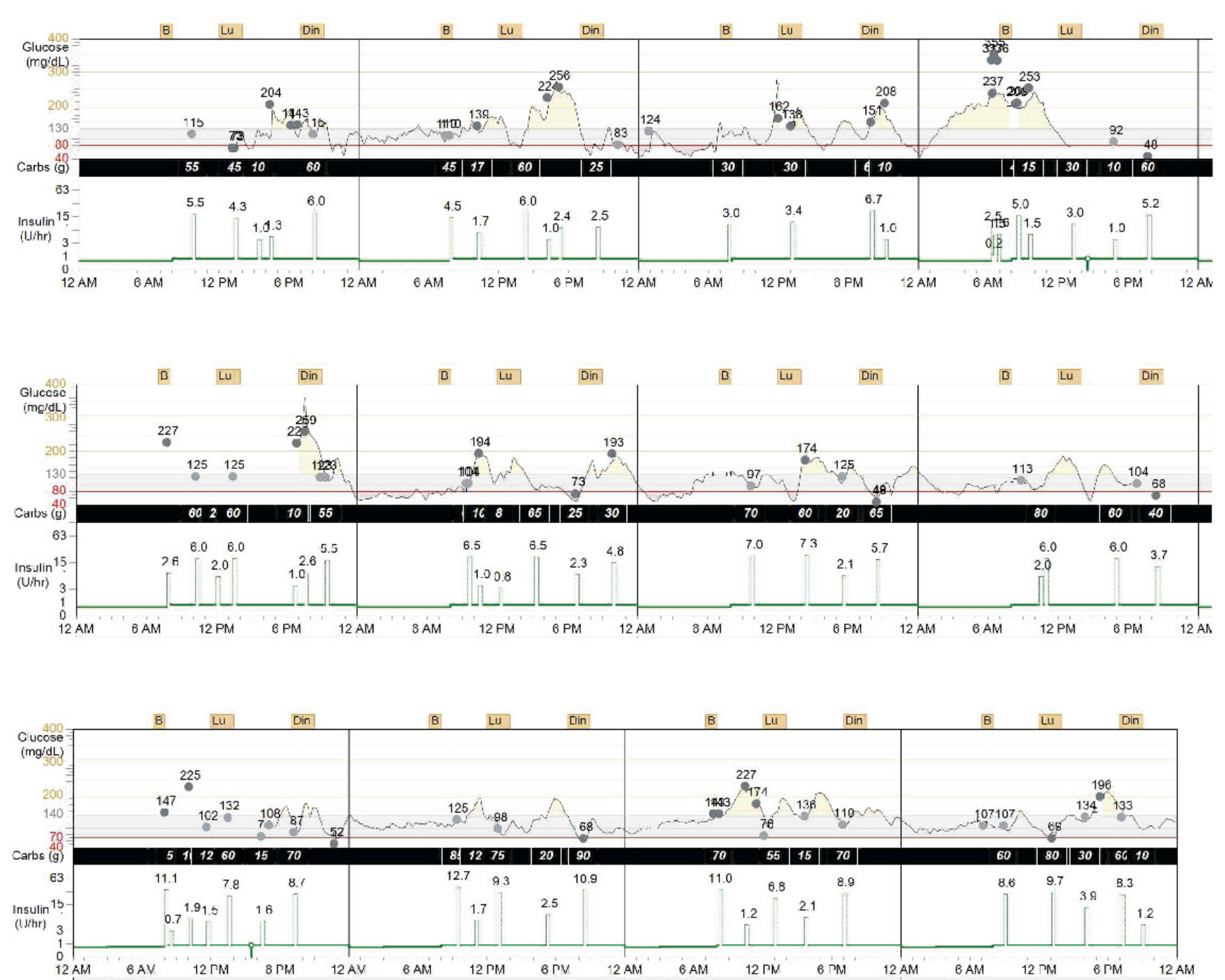

D

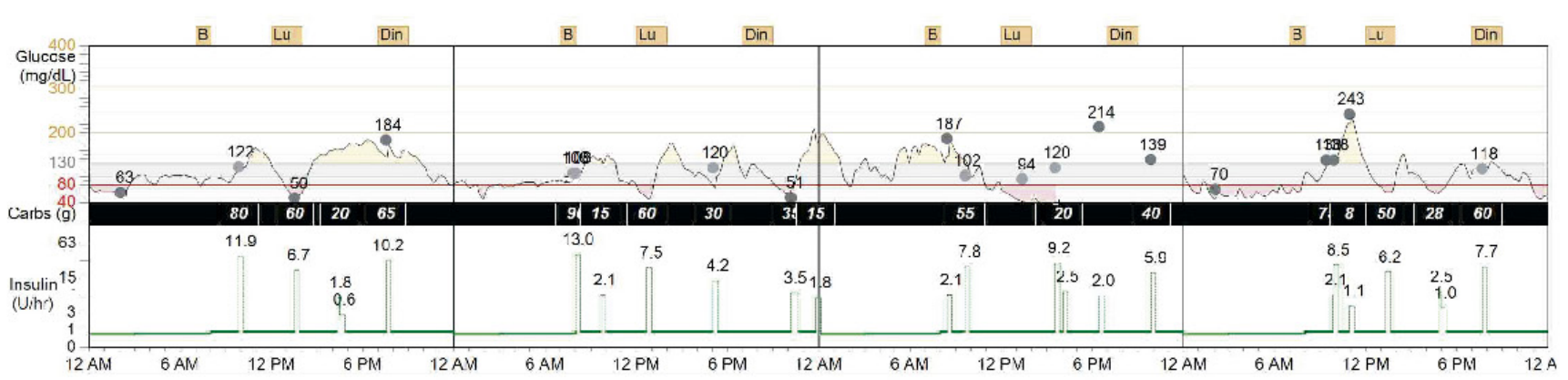

$\mathrm{E}$

Figure 1: Glycemic fluctuations during early first trimester (A), late first trimester (B), early second trimester (C), late second trimester (D), and early third trimester (E) using the continuous monitoring system. 

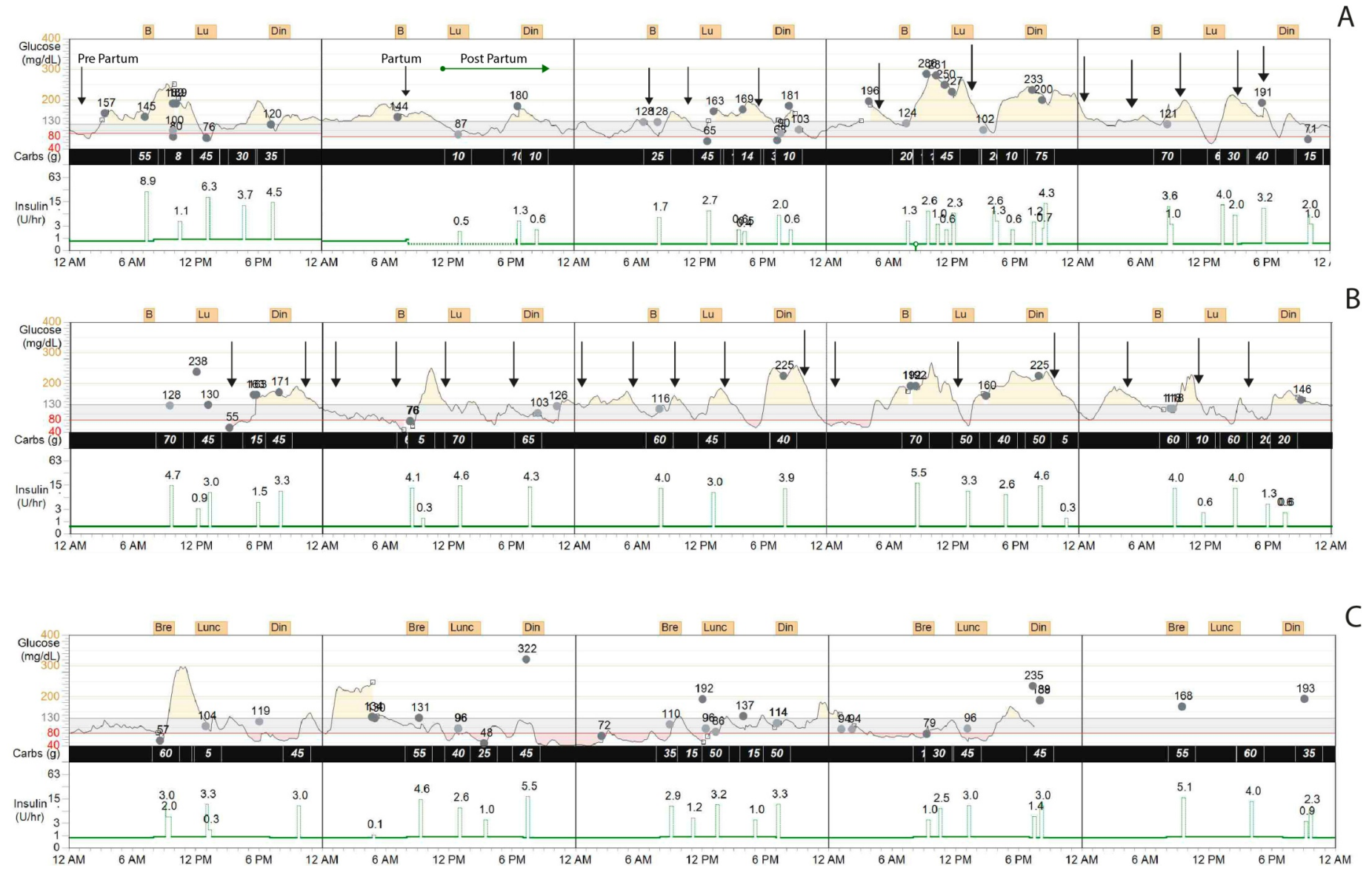

Figure 2: Glycemic profile in the late third trimester, partum and early post partum periods $(A)$, one month (B) and six months (C) post delivery using the continuous monitoring system.

\section{References}

1. Macintosh MC, Fleming KM, Bailey JA, et al. Perinatal mortality and congenital anomalies in babies of women with type 1 or type 2 diabetes in England, Wales, and Northern Ireland: population based study. BMJ. 2006; 333: 177-262. doi: $10.1136 /$ bmj.38856.692986

2. Kitzmiller JL, Buchanan TA, Kjos S, Combs CA, Ratner RE: Pre-conception care of diabetes, congenital malformations, and spontaneous abortions. Diabetes Care. 1996; 19: 514-541. doi: 10.2337/diacare.19.5.514

3. Suhonen L, Hiilesmaa V, Teramo K. Glycemic control during early pregnancy and fetal malformations in women with type 1 diabetes mellitus. Diabetologia. 2000; 43: 79-82. doi: 10.1007/s001250050010

4. Metzger BE, Lowe LP, Dyer AR, et al. HAPO Study Cooperative Research Group. Hyperglycemia and adverse pregnancy outcomes. N Engl J Med. 2008; 358: 1991-2002. doi: 10.1056/NEJMoa0707943

5. Blumer I, Hadar E, Hadden, DR, et al. Diabetes and pregnancy: an endocrine society clinical practice guideline. J Clin Endocrinol Metab. 2013; 98: 4227-4249. doi: 10.1210/jc.2013-2465

6. Rosenn B, Siddiqi TA, Miodovnik M. Normalization of blood glucose in insulin-dependent diabetic pregnancies and the risks of hypoglycemia: a therapeutic dilemma. Obstet Gynecol Surv.1995; 50: 56-61.

7. Rosenn BM, Miodovnik M, Holcberg $G$ et al. Hypoglycemia: the price of intensive insulin therapy for pregnant women with insulin-dependent diabetes mellitus. Obstet Gynecol. 1995; 85: 417-422.

8. Kyne-Grzebalski D, Wood L, Marshal SM, Taylor R. Episodic hyperglycemia in pregnant women with well-controlled Type 1 diabetes mellitus: a major potential factor underlying macrosomia. Diabetic Medicine. 1999; 16: 702-706. doi: 10.1046/j.1464-5491.1999.00131.x

9. Cohen O, Keidar N, Simchen M, et al. Macrosomia in well controlled CSII treated Type I diabetic pregnancy. Gynecol Endocrinol. 2008; 24: 611613. doi: 10.1080/09513590802531062
10. Ceriaello A, Ihnat MA. Glycemic variability: a new therapeutic challenge in diabetes and the critical care setting. Diabetic Medicine. 2010; 27: 862867. doi: 10.1111/j.1464-5491.2010.02967.x

11. Cyganek K, Hebda-Szydlo A, Katra B, et al. Glycemic control and selected pregnancy outcomes in type 1 diabetes women on continous subcutaneous insulin infusion and multiple diaily injections: the significance of pregnancy planning. Diabetes Technol Ther. 2010; 12: 4147. doi: 10.1089/dia.2009.0081

12. Roeder HA, Moore TR, Ramos GA. Insulin pump dosing across gestation in women with well-controlled type 1 diabetes mellitus. Am J Obstet Gynecol. 2012; 207(4): 324-328. doi: 10.1016/j.ajog.2012.06.029

13. Farrar $D$, Tuffnell DJ, West J. Continuous subcutaneous insulin infusion versus multiple daily injections of insulin for pregnant women with diabetes. Cochrane Database Syst Rev. 2007: CD005542. doi: 10.1002/14651858.CD005542.pub2

14. Blevins TC, Bode BW, Garg SK, et al. Statement by the American Association of Clinical Endocrinilogists Consesus Panel on Continous Glucose Monitoring. AACE Consensus Statement. Endocrine Practice. 2010; 16: 731-745.

15. Grunberger G, Abelseth JM, Bailey TS, et al. Consensus statement by the american association of clinical endocrinologists/american college of endocrinology insulin pump management task force. Endocrine practice: official journal of the American College of Endocrinology and the American Association of Clinical Endocrinologists. 2014; 20(5): 463-489. doi: :10.4158/EP14145.PS

16. Evers IM, Ter Braak Ewmt, De Valk HW, et al. Risk indicators predictive for severe hypoglycemia during the first trimester of type 1 diabetic pregnancy. Diabetes Care. 2002; 25: 554-559.

17. Murphy HR, Rayman G, Duffield K, et al. Changes in the glycemic profiles of women with type 1 and type 2 diabetes during pregnancy. Diabetes Care. 2007; 30: 2785-2791. doi: 10.2337/dc07-0500 
18. Mukhopadhyay A, Farrel T, Fraser RB, Bolarinde O. Continuos subcutaneous insulin infusion $v$ s intensive conventional insulin therapy in pregnant diabetic women: a systematic review and metaanalysis of randomized, controlled trials. Am J Obstet Gynecol. 2007; 197: 447-456. doi: 10.1016/j.ajog.2007.03.062

19. Cyganek K, Hebda-Szydla A,Skupien J. et al. Postpregnancy glycemic control and weight changes in type 1 diabetic women. Diabetes Care. 2013; 36: 1083-1087. doi: 10.2337/dc12-1340

20. Bentley-Lewis R, Goldfine AB, Green DE, Seely EW. Lactation after normal pregnancy is not associated with blood glucose fluctuations. Diabetes Care. 2007; 30: 2792-2793. doi:10.2337/dc07-1243

21. Tigas S, Sunehag A, Haymond MW. Metabolic adaptation to feeding and fasting during lactation in humans. J Clin Endocrinol Metab. 2002; 87: 302-307.
22. Kjos SL, Henry O, Lee RM, Buchanan TA, Mishell DR Jr. The effect of lactation on glucose and lipid metabolism in women with recent gestational diabetes. Obstet Gynecol. 1993; 82: 451-455.

23. Grunderson EP, Hedderson MM, Chiang V, et al. Lactation intensity and postpartum maternal glucose tolerance and insulin resistance in women with recent GDM. Diabetes Care. 2012; 35: 50-56. doi: 10.2337/dc111409

24. L Saez-de-Ibarra, R Gaspar, A Obesso, L Herranz. Glycaemic behaviour during lactation: postpartum practical guidelines for women with type 1 diabetes. Practical Diabetes International. 2003; 8: 271-275. doi: 10.1002/ pdi.529

25. Riviello C, Mello G, Jovanovic LG. Breastfeeding and the basal insulin requirements in type 1 diabetic women. Endocrine Practice. 2009; 15: 187-193. doi: 10.4158/EP.15.3.187 